\title{
LISBOA, METRÓPOLE POLICÊNTRICA E FRAGMENTADA
}

\author{
TERESA BARATA SALGUEIRO ${ }^{1}$
}

\begin{abstract}
Resumo - Este texto trata da estruturação da AML, particularmente na actual fase marcada pelo avanço de lógicas globais. O reforço das competências das autarquias, o maior equipamento dos núcleos suburbanos, sujeitos agora a menor pressão demográfica, o aumento do consumo e da motorização das famílias e o aparecimento de novas formas de comércio e de novos padrões de localização e relocalização de actividades convergem na mutação da organização metropolitana traduzida na perda de importância do centro tradicional e na evolução para uma estrutura policêntrica. Esta mudança acompanha a evolução da cidade industrial para a pós-industrial e traduz-se numa fragmentação socio-espacial por perda da unidade funcional baseada nas interdepências entre áreas especializadas, e no crescimento de uma pluralidade de grupos sociais cuja identidade se constrói e revela nos objectos, nos sítios e, principalmente, nos símbolos.

Focam-se essencialmente três processos de mudança, a desconcentração de pessoas e actividades com grande aumento da área urbana; o desenvolvimento de novas centralidades, e a recentralização selectiva.
\end{abstract}

Palavras-chave: reorganização urbana, fragmentação, policêntrismo.

\begin{abstract}
TRENDS TO POLICENTRISM AND FRAGMENTATION IN LiSBON - In this paper, we study the transformations of the spatial organisation of the Lisbon Metropolitan Area. The main focus is on the present restructuring dominated by three main processes. Firstly decentralisation of housing and economic activities, secondly development of new centralities, high status areas with very good accessibility and great attractivity, mainly occupied by office buildings or mixed-use developments (offices, retail, hotel, luxury apartments) in the inner city or close to new suburban highways; and, finally, selective gentrification and re-use of the central city, either by high income housing or modern services.

The evolution outlined can achieve the replacement of a strong centralised metropolis with unequal distribution of employment and services between metropolitan core and suburban rings by a new multicentered structure. This evolution goes along with the transition from the industrial to the post-industrial city that brings the fragmentation of the socio-spatial structure with a juxtaposition of territories. In the economic sense the city loses its functional unity made of interdependent specialised territories. In the social sense this reflects the rise in the number and differentiation due to the increase of opportunities and choices once the position in the labour market is no more sufficient to define social position and people look for and build their identification through goods, places and their symbols.
\end{abstract}

1 Professora Catedrática da Universidade de Lisboa, Investigadora do C.E.G., Fac. Letras, Cidade Universitária, 1699 Lisboa Codex. Tel: (351-1) 79651 62; fax: (351-1) 7960063. 
Key-words: Urban Restructuring, post industrial city, fragmentation, multicentered.

Este texto trata da estruturação da metrópole lisboeta detendo-nos principalmente na fase actual marcada pelo avanço das lógicas globais, pelo policentrismo da estrutura sujeita a processos de descentralização e recentralização selectiva, num quadro de fragmentação crescente do território.

\section{1 - PERÍODO DE FORMAÇÃO METROPOLITANA}

A área metropolitana tal como hoje existe estruturou-se essencialmente nas décadas de 50 a 70 em resultado de importantes movimentos migratórios, todavia diferentes ao longo do período. Até 1975 Lisboa acolhe migrantes das áreas rurais do país que na grande cidade procuram emprego e melhores condições de vida de modo que em 1981 ainda $42 \%$ dos residentes tinham nascido noutras regiões do país. Este crescimento demográfico explica-se por alterações ocorridas na estrutura produtiva nacional e regional, relacionadas com a maior abertura do país ao estrangeiro depois da segunda guerra, e consequente redefinição da posição do país no quadro da divisão internacional do trabalho. Assiste-se ao desenvolvimento de um sector industrial de base alicerçado na siderúrgia, metalomecânicas, construção e reparação naval, com forte presença na região de Lisboa, e à expansão de sectores industriais com importante componente exportadora, baseados essencialmente no baixo custo da mão obra.

Depois de 1975, com a independência das colónias africanas, chegam a Portugal colonos e nativos desses territórios que inauguram um fluxo de migrantes do Sul alimentado primeiro pelas guerras civis que entretanto assolam aqueles territórios, mas tendendo depois a ampliar-se nas motivações e no âmbito espacial.

Para além da dinamização da indústria regional, o desenvolvimento da economia do país contribui também para a expansão dos serviços em Lisboa devido à forte centralização política e económica existente.

A formação metropolitana caracteriza-se por uma estrutura fortemente centralizada na qual Lisboa polariza grande parte do emprego nos serviços e mesmo na indústria, apesar da formação de algumas zonas de indústria pesada na periferia, e pelo crescimento das assimetrias entre o centro metropolitano e as periferias carenciadas. Efectivamente, o importante fluxo migratório e a reestruturação da área central, onde a terciarização expulsa residentes, determinam uma taxa de crescimento muito rápido da coroa suburbana que os serviços à população e o comércio não acompanham, traduzida numa grande dependência destas áreas em relação ao centro para equipamentos escolares, de saúde, culturais e recreativos, e mesmo para o comércio que não seja de primeira necessidade.

O crescimento demográfico explosivo reflecte-se também no agudizar do problema da habitação. Face à diminuta produção social de alojamentos as barracas e os bairros clandestinos crescem, as primeiras principalmente na cidade, enquanto os segundos são mais frequentes na coroa suburbana. No início dos anos 70 estimava-se que viviam em condições precárias ou substandard entre 12 a $20 \%$ dos 
residentes na área metropolitana. A área metropolitana é marcada ainda por uma forte dualidade em termos de acesso a equipamentos, infraestruturas e serviços entre a cidade consolidada e as áreas marginais por um lado, entre a cidade centro e as coroas periféricas por outro.

Trata-se ainda de uma cidade com subúrbios hegemonizados pelo núcleo central segundo o modelo de zona urbana compacta, na continuidade da tradição urbana do mediterrâneo, com fraca mobilidade individual e muito dependente do transporte colectivo. Se em termos brutos a densidade não é muito alta devido à importância das manchas verdes, terrenos florestais, agrícolas e não construídos, bem como à extensa toalha fluvial do Mar da Palha, nas zonas efectivamente construídas a densidade cresce devido à tendência para a compactação do tecido (desenvolvimento em altura e poucas áreas livres nas novas áreas residenciais) numa cidade que cresce essencialmente às mãos da especulação.

A forma urbana é estrelada, mais desenvolvida na margem norte e ao longo das linhas de comboio suburbano.

Em termos de comércio e serviços pessoais, afirma-se então uma estrutura baseada numa hierarquia de centros desde o nível local até ao centro metropolitano, $C B D$, localizado na Baixa, passando pelo centro de bairro e, posteriormente, pela individualização de centros subregionais ou de comunidade. Esta estrutura é completada pela existência de alguns desenvolvimentos lineares de comércio especializado principalmente em móveis, electrodomésticos ou material de construção (Rua Almirante Reis, Rua de S.José - Santa Marta, Rua D. Pedro V e Rua de S.Bento) e de algumas áreas especializadas em actividades de lazer e ócio, no seio do centro principal ou nas suas margens (zona portuária do Cais do Sodré, Rossio-Av da Liberdade), para além dos jardins e parques periféricos. Em termos gerais não se afasta dos modelos de organização enunciados por PROUDFOOT (1937) e BERRY (1963).

Entretanto, no início dos anos 60, Lisboa conhece uma inovação em termos comerciais, o livre serviço e os primeiros supermercados. Este tipo de comércio aparece na área central e nos bairros residenciais de maior nível económico difundindo-se muito lentamente ao longo da década. A inauguração da primeira linha de metropolitano marcará novos rumos em termos de acessibilidade. Igualmente com desenvolvimento lento os seus profundos efeitos só vão ser visiveis mais tarde.

\section{2 - A TRANSIÇÃO}

A cidade burguesa edificada na segunda metade de oitocentos rompeu com a tradição secular de ligação de Lisboa com o rio Tejo privilegiando a construção de boulevards o os bairros novos que estes suportavam em direcção ao Norte, mas manteve o essencial das actividades de comércio e serviços na Baixa, entre o porto e as gares ferroviárias. As linhas de transporte colectivo em meio fixo, eléctrico e comboio, reforçaram a dominância regional deste centro que progressivamente se consolidou como o centro de comércio e negócios de nível mais alto. Esta hegemonia económica será desafiada com a aproximação do último quartel do 
século XX. Efectivamente, a década de 70 é marcada por importantes sinais de mudança, uns mais visíveis do que outros, em que se cruzam as circunstâncias da crise económica geral do regime fordista, o qual só parcialmente aliás estava instalado na formação socioespacial portuguesa, com a mudança do regime político em Portugal.

A mudança de regime com a instalação da democracia em 1974 ocorre num período de crise do capitalismo mundial e altera radicalmente as condições sócio-económicas do país. Em paralelo com um amplo movimento de nacionalizações registam-se importantes progressos no domínio da segurança social e do alargamento da escolarização. Crescem os salários mas diminui drasticamente o investimento privado, a produção e o crescimento económico. Em termos de investimento muitas iniciativas desencadeadas no princípio desta década, que conheceu grande aceleração da inflação e forte especulação, serão travadas durante quase dez anos para só depois de 1985 se precipitarem em ritmo veloz aproveitando então das novas condições do ambiente económico e da mudança social ocorrida.

Entre 1975 e 1985 verifica-se a subida do nível de vida e abertura para novos hábitos de vida e consumo devido a uma mudança social muito profunda que actuou ao nível das mentalidades e dos comportamentos, ao nível da organização e das relações na família, na escola, nos bairros e na sociedade em geral. O grande progresso nas redes rodoviárias e a expansão do parque automóvel criaram novos padrões de mobilidade das populações que conjugados com o aumento dos rendimentos das famílias, da informação, e a maior abertura às inovações permitiram que o consumo disparasse e adoptasse características novas.

Com a gestão democrática os municipíos assumem novos poderes e competências. Inicialmente a sua acção procura responder às graves carências herdadas em termos de saneamento, de habitação e de circulação, em paralelo com a sua própria organização interna, mas progressivamente diversifica-se e muda. Integra de modo mais nítido os aspectos económicos e usa o planeamento do território como instrumento de gestão que pretende não simplesmente resolver problemas mas tornar competitivos os territórios. Importam-se métodos da gestão empresarial para o território cuja condução se torna mais ofensiva e mais compartilhada, designadamente associando o Estado local com organismos privados.

Assistiu-se progressivamente à consolidação dos territórios suburbanos favorecida também pelo crescimento relativamente menos intenso de muitas áreas que então recebem as necessárias infraestruturas e equipamentos, ganhando portanto maior autonomia e menor dependência em relação ao centro de Lisboa, tanto mais que se acentuam os movimentos de descentralização e relocalização a partir da cidade centro envolvendo um leque mais diversificado de funções e actividades.

No que respeita aos sítios de comércio e consumo as mudanças mais significativas da década de 70 referem-se a três aspectos:

- O aparecimento das primeiras grandes superficies alimentares, com mais de $2500 \mathrm{~m}^{2}$, dotadas de parque de estacionamento e com tendência para localizações periféricas, ainda na coroa urbana (Alcântara, Campo Grande) ou mesmo já suburbana (Venda Nova, Almada, Cascais, Portela). 
- A inauguração dos primeiros centros comerciais (Apolo70, Alvalade, Imaviz) com loja âncora, por vezes cinema, acompanhando a deslocação do centro e a rede de metropolitano, por vezes localizados num sítio de ruptura de transporte entre esta rede e os autocarros suburbanos, como em Alvalade. Trata-se ainda de realizações modestas que oferecem comércio e lugares de restauração nas novas zonas de emprego terciário, atrem público aos cinemas com várias sessões, incluindo uma à meia noite, e às lojas abertas até tarde e ao domingo.

- Reforço e diversificação do comércio suburbano, designadamente nas sedes de concelho e localidades mais importantes, seja na forma tradicioanl de comércio de rua, seja através de grandes superfícies.

Na cidade começa o declínio do centro tradicional de comércio e a evolução do centro de negócios para norte onde se virá a afirmar um novo centro na zona do Marquês de Pombal-Avenidas Novas.

Deste modo, esta fase de transição marca o início do fim da cidade monocêntrica e homogeneizada pela Baixa e lança as bases da metrópole policêntrica que se tornará mais nítida no último período considerado.

\section{3 - A METRÓPOLE POLICÊNTRICA}

A integração de Portugal na Comunidade Europeia em 1986 culmina o esforço de abertura do país ao exterior e do novo relacionamento internacional empreendido depois de 1974 e simboliza também a estabilidade da nova situação democrática. O investimento directo estrangeiro cresce substancialmente e muda de objectivos em relação a fases anteriores, privilegiando o sector financeiro, onde entretanto se procedia à venda da participações públicas, e o consumo em sentido lato. De facto cresce significativamente o investimento no comércio, em parte devido à presença de grandes distribuidores estrangeiros (BARATA SALGUEIRO, 1992-a), e na produção do espaço urbano com o boom do investimento transnacional no imobiliário de escritórios (BARATA SALGUEIRO, 1992-b, 1994).

A integração europeia veio ainda reforçar o carácter atractivo do país, visto por muitos como uma porta de entrada na sonhada Europa. Deste modo, amplia-se a área de recrutamento de migrantes bem como a sua qualificação (MALHEIROS, 1996).

Nos anos 80 a população da área metropolitana cresce menos, cerca de 50 mil habitantes, mas Lisboa-cidade perde $18 \%$ de residentes e registam-se profundas mutações na região metropolitana que se podem resumir a três processos, forte desconcentração de residências e actividades, desenvolvimento de novas centralidades e acções de recentralização selectiva. Assim, e no que respeita aos serviços, designadamente nos serviços às empresas e mesmo nos pessoais de nível alto nota-se a pouca importância da Baixa, o desenvolvimento de um novo centro terciário, e a formação de novas centralidades periféricas.

Efectivamente a Baixa perdeu peso em relação ao novo centro terciário que se afirmou na zona do Marquês de Pombal-Avenidas Novas. Com o avanço da sociedade de serviços o centro tradicional não teve capacidade de resposta para as novas procuras de espaço de escritórios e as empresas instalam-se em áreas mais amplas e 
com menos limitações a norte onde definem um novo centro. Muito extenso em superfície, tendo passado por numerosos processos de renovação do edificado que conduzem ao aumento da densidade de ocupação e à substituição de residentes ${ }^{2} \mathrm{e}$ de comércio de proximidade tradicional por escritórios, aqui se encontram 39\% das empresas de serviços e se concentram os novos exemplares arquitectónicos que mudam a imagem da cidade, muitos dos novos símbolos do poder e do prestígio das empresas que recorrem ao volume da construção, à arquitectura e ao nome do projectista para o mostrar. É a nova cidade das empresas (RELPH, 1987), a verticalização da metrópole (SOUZA, 1994) o terreno escolhido pelo capital para se refugiar no circuito secundário da valorização (HARVEY, 1985) e para procurar e dirigir a nova forma de acumulação.

Paralelamente a esta área central nova vemos multiplicar-se na coroa urbana e nas periferias novas centralidades, pólos de concentração terciária que associam por vezes habitação, dotados de muito boa acessibilidade ao automóvel, que oferecem espaços de qualidade acolhendo empresas modernas com frequência internacionalizadas, contribuindo para centrar aqui importante capacidade de inovação, poder de decisão e controlo. Pontos atractivos para diversos fluxos o seu prestígio acompanha o das empresas instaladas. Localizam-se na coroa do centro (do Amoreiras ao Colombo ou ao Lumiar, passando pela avenida dos Combatentes e Torres de Lisboa) e na área suburbana, associados à produção de espaço urbano valorizado pela construção de novas infraestruturas rodoviárias (auto-estradas, vias rápidas) ou pela renovação de antigas áreas industriais. Caso particular são os parques tecnológicos associados a universidades ou institutos de investigação que procuram sinergias decorrentes da proximidade entre a investigação e as empresas, e pretendem apoiar a criação de empresas inovadoras especialmente pelo recurso a novas tecnologias.

Praticamente todos os parques de escritórios existentes ou em construção na região de Lisboa se localizam perto da auto-estrada de Cascais e nas razões aduzidas pelos promotores para essa escolha destacam-se a proximidade ao aeroporto e ao eixo suburbano habitado por maior número de estrangeiros e quadros superiores. Isto mostra a forte orientação externa destes empreendimentos, por um lado, e a importância do capital social na valorização do território e, por consequência, na escolha dos sítios empresariais de qualidade, por outro.

Os aspectos mais salientes da actual estrutura do comércio retalhista, que se traduz numa diversificação da oferta, compreendem o declínio do comércio tradicional de proximidade e a a polarização de tamanhos dos estabelecimentos no sector alimentar com a emergência de grandes superfícies alimentares e de modernos pontos de venda de proximidade, a manutenção das faixas especializadas, o aparecimento de centros alternativos à Baixa para a procura menos frequente, e a associação crescente entre novos espaços de comércio e de lazer.

2 A freguesia de Fátima perdeu 15716 residentes, isto é quase metade da sua população, entre 1960 e 1991. 
Nos últimos anos verificou-se uma acentuada quebra no comércio alimentar tradicional de proximidade face à concorrência dos supermercados, das modernas lojas de conveniência e de desconto, dos hipermercados médios e grandes mais distantes. A diminuição no número de estabelecimentos que deve continuar a acentuar-se no futuro ${ }^{3}$ próximo foi acompanhada pela concentração das vendas nas grandes superfícies.

Paralelamente à multiplicação de grandes superficies na periferia dos aglomerados, nos meados dos anos 90, assiste-se à proliferação das lojas de desconto de proximidade, bem como à modernização e qualificação de muitos estabelecimentos tradicionais, por vezes fruto da sua adesão a formas de comércio associado.

As faixas especializadas reforçaram a importância na estrutura comercial da cidade e também sofreram evolução. A avenida Almirante Reis continua como eixo especializado no comércio de móveis e electrodomésticos, mas exemplifica uma situação de comércio étnico, uma vez que muitas das lojas são geridas por pessoas de origem indiana, tal como o comércio de quinquilharias e brinquedos da zona do Martim Moniz.

Noutros eixos onde tradicionalmente se processava também o comércio de mobiliário, Rua de S.José-Santa Marta, Rua de D. Pedro V e Rua de S.Bento, verificou-se uma selecção no sentido do aumento da qualidade e da especialização em antiguidades. Afirmou-se ainda um novo eixo comercial especializado em objectos e artigos de uso pessoal, hoje ao nível de centro regional, nas avenidas Guerra Junqueiro e Roma. Aqui se localizam alguns grandes estabelecimentos (megastores) de cadeias internacionais e vários franchisings. A avenida da Liberdade que é o principal acesso à Baixa e nunca foi um eixo comercial começou a receber comércio de gama alta em ligação com a renovação dos edificios, às vezes com uma pequena galeria comercial, que atraem empresas de prestígio e empregam quadros com capacidade financeira e ciosos da sua aparência.

Em contrapartida, algum comércio tradicional das faixas, como o dos móveis, materiais de construção, ferragens e bricolage, tende hoje a aparecer em grandes lojas especializadas com localização periférica, muitas vezes junto de hipermercados, tal como sucede com os brinquedos, artigos de decoração, equipamento e material para jardim.

Nos ramos não diários a oferta continua muito numerosa e diversificada em termos de dimensão, desde a loja exígua à grande unidade com mais de $1000 \mathrm{~m}^{2}$. Os grandes armazéns que fizeram sucesso no princípio do século, cedo entraram em decadência mas actualmente aparecem megastores de vestuário, brinquedos, discos, livros tanto na Baixa como na avenida Guerra Junqueiro e no CascaiShopping, para além das grandes superfícies especializadas já referidas. Para a modernização dos novos espaços de consumo tem contribuído ainda a expansão do franchising. Muitos dos bens não diários e de alimentação rápida são

3 Segundo previsões da Nielsen (1996) nos próximos três anos encerrarão cerca de um terço das mercearias actualmente existentes no país de modo que no ano 2000 o conjunto dos hiper e supermercados com cerca de 1000 pontos de venda dominará $86.5 \%$ do negócio avaliado em 1.5 biliões de escudos. 
apresentados no quadro deste regime traduzindo novas formas de gestão e de concentração empresarial (BARATA SALGUEIRO, 1996) e contribuindo para a uniformização das paisagens comerciais e para a homogeneização dos consumos.

A oferta moderna surge nas áreas residenciais, designadamente nos núcleos suburbanos, onde reforça a autonomia dos vários centros, podendo ainda classificar-se no quadro de uma hierarquia de centros, mas também ocorre em «espaços vazios» da periferia e nas áreas empresariais e de escritórios, servindo por vezes de referência a novas áreas empresariais, como sucede na de Alfragide, contribuindo para a redução da importância dos princípios que fundamentavam a estrutura da oferta numa hierarquia de centros de diferentes níveis. Deste modo pode concluir-se que, em paralelo com o aumento da diversidade, se registou uma importante desconcentração da actividade comercial e multiplicação dos sítios de comércio. Como as tendências para a desconcentração são muito fortes pode dizer-se que, independentemente dos resultados da reconstrução do Chiado e da reabilitação, a Baixa não voltará a ser o centro de Lisboa.

As áreas residenciais não escapam aos processos de recomposição urbana. Antes pelo contrário contribuem de modo activo para aquelas mudanças. Dentro da diversidade de situações podemos considerar três aspectos importantes para a definição de novos produtos para classes médias altas, condomínios fechados com diversas tipologias e padrões de localização, apartamentos reabilitados na cidade consolidada, e aumento da oferta de moradias, principalmente na coroa suburbana ou periurbana, embora havendo alojamentos que partilham dois ou três destes aspectos.

O condomínio remete para a existência de espaços comuns, portanto propriedade colectiva, e o condomínio fechado acentua a restrição ou o controlo do acesso ao conjunto. A sua expansão ocorre em paralelo com o aumento da segmentação social, o valor emblemático atribuído à residência e o crescimento da insegurança.

Trata-se no geral de conjuntos de edifícios com espaços de lazer comuns, jardins, piscinas, campos de jogos. Na cidade o complexo tem três ou quatro edifícios de apartamentos desenvolvidos em altura e as áreas de lazer reduzem-se. Já na coroa periurbana podem oferecer também moradias isoladas ou em banda e dispôr de áreas de jogos extensas, incluindo golfe.

Sem espaço para discutir aqui o sentido destas novas formas de habitar, existem três pontos que gostaríamos de destacar e que dizem respeito à segurança, ao incremento de serviços associados ao alojamento e à privatização ou fruição restrita de espaços de actividade colectiva.

A segurança expressa a necessidade de se fechar entre iguais como defesa dos estranhos que são vistos como uma ameaça numa sociedade que se fragmenta e des-solidariza.

O aumento dos serviços conexos com o alojamento mostra, por um lado, o distanciamento em relação ao zonamento funcional do modernismo com a tendência para a mistura de funções; e, por outro, a evolução do próprio mercado destes produtos com a sua invasão pela lógica do consumo: cada vez mais a transação envolve algo mais que transcende os produtos concretos. Para além das 
características intrínsecas da casa e da localização, vende-se com ela também um sinal de estatuto social, vizinhos, facilidades desportivas, um clube, áreas verdes. A necessidade constante de encontrar produtos novos expressa-se no alargamento dos serviços que compõem o «pacote residencial», mas responde também com certeza à importância crescente do lazer e do ambiente na expressão do self numa época de maior perturbação na definição das identidades que HARVEY associa à compressão espacio-temporal.

A privatização de espaços tradicionalmente colectivos decorre das mesmas lógicas de consumo e fragmentação do espaço e permite-nos dizer que de certo modo os condomínios fechados são o equivalente habitacional do centro comercial pois implicam acesso controlado a espaços comuns de utilização colectiva re-criados no seio da propriedade privada.

A habitação nova ou reabilitada em áreas prestigiadas e revalorizadas da cidade suporta o processo de nobilitação correspondente à revalorização da centralidade para residência de grupos sociais abastados. Cobre uma diversidade de situações desde o apartamento grande ao prédio modernizado e reconstruído e ao conjunto de prédios totalmente novo, às vezes sob forma de condomínio fechado, mas predominando a localização na cidade centro, em áreas prestigiadas pelo património edificado, pelo capital cultural e social dos residentes, pelas vistas, eventualmente pela modernidade, numa oferta que privilegia a qualidade da vivência na cidade.

A oferta de moradias que deverá crescer substancialmente nos próximos anos, estende-se às classes médias cobrindo também uma grande diversidade de situações, desde os fogos nos antigos bairros sociais da cidade, hoje plenamente integrados na malha urbana e valorizados, ou nos bairros clandestinos da periferia, às construções novas em extensão principalmente na coroa suburbana ou periurbana.

Ao contrário da nobilitação associada à reabilitação, que é um exemplo de tendência central, o mercado de residência unifamiliar é tipicamente de coroa e a sua expansão incrementa a periferização dos estratos médios e altos e reforça a componente «periférica» da reorganização urbana.

Se tivermos ainda em conta a persistência de importantes núcleos de casas abarracadas, agora cada vez mais ocupadas por minoria étnicas, e as áreas-problema em que se converteram alguns dos grandes conjuntos de habitação social produzidos pelo ex-FFH vemos que a observação da metrópole na perspectiva do alojamento revela que aumentou consideravelmente a diversidade da escolha e dos produtos e que a nova metrópole é, do ponto de vista socio-espacial, muito fragmentada. A diversidade dos produtos em termos de características dos alojamentos, da localização, dos serviços conexos, do preço, do estatuto social que conferem responde naturalmente ao aumento da complexidade da estrutura social e às novas funções atribuídas ao alojamento na sociedade do consumo. 
Existe portanto uma mutação da estrutura metropolitana traduzida na perda de importância do centro tradicional e evolução para uma situação policêntrica e de fragmentação dos territórios.

A cidade industrial constituiu-se na base de áreas funcionalmente diferenciadas e interdependentes, fortemente polarizadas e comandadas por um centro. Com o aumento da extensão das áreas urbanas e as novas condições de acessibilidade, com a sobreposição de lógicas supralocais às locais, o aumento da diversidade das famílias, das empresas e dos produtos rompe-se esta continuidade. A cidade fragmenta-se e perde a sua unidade funcional. A fragmentação corresponde à existência de enclaves distintos e sem continuidade com a estrutura socio-espacial que os cerca. Traduz o aumento intenso da diferenciação e a existência de rupturas entre os vários grupos que substituem a continuidade anterior sendo particularmente visivel no domínio da estrutura social e no território. Do ponto de vista social, cresce a segmentação não permitindo fazer uma leitura unidimensional nem hierárquica do espaço social porque as tendências para uma quase pulverização dos grupos requerem uma leitura multidimensional, como um caleidoscópio.

Diminui a importância da posição dos indivíduos no sistema de produção como base para a definição da estratificação social e da apropriação do território e o consumo tem na nova estruturação social um papel crescente. O consumo de objectos, e mais ainda o dos signos, faz parte da composição da identidade dos consumidores ao revelar o que eles são e ao fazê-los pertencer a um grupo que partilha esses sentidos. «Os objectos prometem contextos para além de ligar os indivíduos aos grupos através da comunicação de sentidos»(SACK, 1992). O próprio território pode ser consumido e usado na composição da identidade, quer dos indivíduos, quer das empresas.

A importância da valorização simbólica dos espaços nos processos de identificação pessoal e mesmo das empresas ora se exerce a nível do sítio, como era habitual na cidade segregada, ora do edifício. Umas vezes é o sítio que fornece a distinção enquanto noutras aparece um prédio de prestígio num sítio pouco valorizado, por isso podemos dizer que se tende para uma apropriação pontual do território em vez da apropriação extensiva (em mancha) tradicional. Isto permite falar numa «desordem espacial das posições sociais» (DONZELOT, JAILLET, 1997).

A interdependência entre áreas funcionalmente diferenciadas está a ser substituída por interdependencias complexas entre bens, serviços e lugares ligados pelos padrões da vida social organizada em e por meio de determinados lugares (URRY, 1995) e a continuidade centro-periferia dá lugar a organizações em rede devido à multiplicação das centralidades associadas aos novos pólos de escritórios e centros comerciais.

Finalmente, podemos dizer que as novas centralidades apresentam um padrão aleatório, simples produto social do jogo das oportunidades no mercado imobiliário pouco regulado. Isto tanto é verdade para os escritórios como para as habitações de luxo. 


\section{REFERÊNCIAS}

Barata Salgueiro, T. (1989) - Novas Formas de Comércio. Finisterra, Revista Portuguesa de Geografia, XXIV (48): 151-217.

BARAta SAlgueiro, T. (1992a) - A integração europeia e as novas formas de comércio. Análise Social, 27 (118-119): 703-721.

BARATA SAlgueiro, T. (1994) - Novos produtos imobiliários e reestruturação urbana. Finisterra Revista Portuguesa de Geografia, XXIX (57): 79-101 e também Revista de Geografia, 1995, 29 (2):53-67.

Barata Salgueiro, T. (1996) - Do Comércio à Distribuição. Rumos de uma Mudança. Celta, Lisboa.

Barata Salgueiro, T. (ed.) (1992b) - Retailing, Public Policy and Urban Retail Planning, Actas Colóquio UGI, Universidade de Lisboa/GECIC, Lisboa.

BerRy, B. (1963) - Commercial Structure and Commercial Blight. Dep. de Geografia da Univ. de Chicago, $\mathrm{n}^{\circ} 85$. Chicago.

CACHINHO, H. (1992) - O comércio a retalho na Área Metropolitana de Lisboa: Patologias e Potencialidades de um Sector em Mutação. Sociedade e Território, 17: 19-37.

CACHINHO, H. (1994) - O comércio a retalho na cidade de Lisboa. Reestruturação económica e dinâmicas territoriais. Finisterra, Revista Portuguesa de Geografia, XXIX (57): 119-144.

CARRERAS, C. (1992) - Consumo y Desarrollo Comercial Urbano. Sociedade e Território, 17: $10-18$.

CARRERAS, C. (1994) - Os novos espaços de consumo em Barcelona. Finisterra, Revista Portuguesa de Geografia, XXIX (57): 103-117.

DonZelot, J.; JAILLET, M. C. (1997) - Les zones urbaines défavorisées en Europe et en Amérique du Nord. Rel. Projecto CDSN/OTAN. Paris. Policopiado.

HARVEY, D. (1985) - The urbanization of capital. Studies in the history and theory of capitalist urbanization. Basil Blackwell, Oxford.

HARVEY, D. (1987) - Flexible accumulation through urbanisation: reflections on 'post-modernism' in the American city. Antipode, 19 (3): 260-86.

HARVEY, D. (1987) - The Condition of PostModernity. An enquiry into the origins of cultural change. Blackwell, Cambridge.

MALHeIRos, J. (1996) - Imigrantes na Região de Lisboa. Os anos da mudança.Colibri, Lisboa.

Mingione, E. dir. (1996) - Urban Poverty and the Underclass. Oxford. Blackwell.

RELPH, E. (1987) - Modern Urban Landscape, Trad. Portuguesa 1990, Edições 70, Lisboa.

SACK, R. (1992) - Place, Modernity and the Consumer's World. A relational framework for geographical analysis. J.Hopkins, Baltimore.

SANTOS, M.e out. (1994) - Território, Globalização e Fragmentação. HUCITEC/ ANPUR. São Paulo.

SousA, M. (1994) - A Identidade da Metrópole. A verticalização em São Paulo. HUCITEC. São Paulo.

URRY, J. (1995) - Consuming Places. Londres. Routledge. 